\title{
Sector informal urbano: crédito y heterogeneidad productiva
}

\author{
Carlos Briones
}

\section{HETEROGENEIDAD DEL SECTOR INFORMAL}

Cuando se analiza el ámbilo productivo y laboral de la informalidad urbana rápidamente pueden identificarse dos grandes rasgos cohesionadores y homogenizadores de la condición socio-económica de los diversos produclores que conforman este "sector".

El primero de esios rasgos es la baja relación capilal-trabajo que presentan la casi lotalidad de establecimientos - que reflejaría las diticultades de acceso a los mercados de capila-; el segundo se presentaría como la exclusión de la mayoría de instancias institucionales de apoyo productivo.

Eslos grandes rasgos, delinirian una homogeneidad relativa para las aclividades inlormales que permitiría segmentar el espacio productivo y al mismo liempo determinar el horizonte para la identificación de las macropolíticas de apoyo al sector.

Sin embargo, esla homogeneidad relaliva no debe de ocultar las prolundas diferencias existentes entre las actividades, los establecimientos y los ocupados del seclor informal. Esta heterogeneidad, delermina en gran medida las polencialidades de crecimiento y transiormación de las unidades económicas de dicho sector; su capacidad de generación de ingresos; su capacidad de creación de empleo asalariado y lambién su capacidad de respuesta trente a diversas políticas económicas.

Los criterios de heterogeneidad son variados, pero en general 
segmentan la estructura productiva del sector en dos grupos de unidades: las que son capaces de sostener un crecimiento y una transformación estructural que les permite pasar al denominado sector moderno y aquellas que desarrollan movilidades empresariales inversas o que en el mejor de los casos se estancan.

A continuación presentamos - a manera de ilustración- los crilerios de heterogeneidad que consideramos más explicativos de las diferentes dinámicas (ascendenles o descendentes) que pueden desarrollar los establecimientos del sector inlormal.

Una primera manera de diferenciarlos (Briones, 1991; Pérez Sainz, 1991) es la de determinar la lógica que ha precedido el proceso de "informalización" o de creación del establecimienlo. Aquí se pueden identificar tres lógicas o tres objetivos: subsistencla; Independencla laboral y escapar de la regulación económico-soclal.

Cuando el molivo es garantizar la subsistencia, se trata por lo general de ocupaciones auto-creadas para posibilitar la reproducción malerial en ausencia de empleo asalariado u otra forma de ingreso y conliguran un universo de unidades unipersonales o familiares con una muy exigua dotación de capital por trabajador. Si la creación ha sido guiada por la lógica de independencia laboral- el eslablecimienlo o la actividad no es originado por la necesidad sino por la expeclativa de mejorar ingresos vis-à-vis los obtenidos como asalariado- en general se configura un segmento de unidades tamiliares y microempresas con una dotación de capilal que puede oscilar desde niveles bajos hasta niveles aceptables con alguna capacidad polencial de crecimiento.

Finalmente si el objetivo de creación ha sido el escapar a la regulación instilucional nos encontramos con un conjunto de microempresas con alta dotación de capital, organización empresarial-capitalista que han sido establecidas para evadir el control fiscal y la legislación laboral, pueden tener más de 4 trabajadores y una alta capacidad de acumulación.

Otro criterio de diferenciación estaría dado por racionalidad socioeconómica que guia al propietario-productor (Zarca, 1982; Briones, 1989). De esta manera, las unidades de producción pueden dividirse en: establecimlentos cuastcapltallstas y establecimlentos de producclón mercantll tradiclonal. Los primeros son por lo general microempresas en las cuales el propietario-productor busca la reproducción ampliada, la ampliación de mercados y la obtención explícila de ganancias. Tienen por lo general alla capacidad polencial de acumulación, cuentan con una aceplable relación capilal-lrabajo y son dirigidas 
predominantemente por ex-asalarlados del sector formal.

Los establecimientos tradicionales eslán formados por unidades familiares y unipersonales, prevalece lo que se conoce como "mentalidad artesanal tradicional" que persigue únicamente la reproducción simple, la estabilidad del "establecimiento" y la búsqueda de un ingreso suliciente y compatible con su modo de vida. Por lo general, los gula una Kojica de subsistencia y presentan baja dotación de capital, pero, como la diferencia se establece por la existencia o inexistencia de una actitud "ernpresarial", pueden existir establecimientos con dotaciones "aceplables" de capilal por trabajador.

La capacidad de acumulación interna del establecimiemlo constituye otro criterio para evidenciar la heterogeneidad del sector informal. Según Krilz (1985) los eslablecimienlos pueden agruparse - de acuerdo a las diferencias de productividades fisicas del trabajo y de sus respectivas capacidades tecnológicas - de la siguiente forma:

-Microempresas de Acumulaclón Normal. Utilizan procesos tecnológicos intensivos en mano de obra que constiluyen alternativas viables y competilivas a técnicas más intensivas en capital. Dada su opción tecnológica, su razón capilal-Irabajo puede considerarse adecuada, tienen una capacidad de acumulación polencial (generación de ganancias) equivalenle al de empresas formales medianas y por tanto desarrollan una acumulación más o menos normal y tienen altas posibilidades de transformación ascendente.

-Microempresas de Acumulaclón Restringlda. La alternativa tecnológica utilizada presenta un dilerencial de productividad vis-à-vis las utilizadas en el seclor moderno para producir productos similares, por los mayores costos unitarios el productor informal debe de sacriticar parte de su margen de "utilidades" generando un proceso de acumulación restringido.

- Microempresas de Acumulación Deliclente. La compensación del diferencial de productividades es realizado mediante la disminución del margen de ganancias (limita pero no elimina la acumulación) y la disminución del nivel del salario unitario promedio, de manera que la posible acumulación es desarrollada por contracción salarial.

-Establecimlenlos de Reproducción SImple. No hay ulilidades pero los ingresos provenientes de la actividad permilen un ingreso promedio que se ubica en una banda delimitada entre el salario promedio de la rama y el salario legal.

-Establecimlento de Reproducclón Deflclente. La alternativa tec- 
nológica es tan primitiva y la dotación de capital tan baja que no existen utilidades y los ingresos generados se sitúan abajo del salario minimo legal.

Otra manera de resaltar la heterogeneidad del sector informal es diferenciar los establecimientos (o las actividades) según los modos de inserción a los mercados lo su tipo de vinculación con la economía capitalista). El tipo de inserción delermina en gran medida las racionalidades socio-económicas de los productores y estimula 0 desestimula la capacidad de acumulación en la medida de que son los mercados los que "validan" los bienes y servicios producidos y al mismo tiempo delerminan las escalas productivas de las unidades económicas. Las diferenles lipificaciones de inserción mercanlil (Pérez Sainz, 1991; Kritz, 1985; Hugon, 1977), pueden agnuparse de la siguiente forma:

-Establecimlentos con Inserclón Mercantll Diferenclada. Operan en espacios mercantiles en donde se producen y comercializan bienes y servicios análogos pero de menor calidad o bien no producidos por el sector moderno. La oferta es por lo general dirigida hacia los consumidores de menores ingresos y las unidades se insertan en "nichos" que pueden ser remanentes de antiguas formas de producción o actividades económicas relacionadas con la tradición "socio-cultural", asi como también "nichos" abiertos por la propia expansión de las actividades productivas del seclor moderno. Aquí se encuentran desde típicas actividades de subsistencia hasta microempresas con alguna capacidad de acumulación, engloba a la mayoría de aquellas actividades económicas que tienen una menor conexión sistémica con la economía capilalista tales como servicios personales, servicios de mantenimiento de bienes durables y producción de bienes y servicios que no circulan en un mercado separado del productor y su clientela.

-Establecimlentos con Inserción Mercantll Competitiva. Operan en los mismos mercados en que ofertan los establecimientos del sector moderno, producen, generalmenle, bienes y servicios finales fundalmentalmente iguales a los del sector moderno pero diferenciados via precios. Por lo común forman parte de ramas productivas competitivas o con estructuras oligopólicas débiles y se desarrollan en "nichos" no cubiertos por la economía capitalista moderna o abiertos por los patrones de consumo que de ella se derivan. Aqui pueden encontrarse servicios de mantenimiento especializados, producción de bienes finales de consumo masivo y servicios no personales sin clienlelas especílicas.

-Establecimientos con Inserción Mercantll Subordlnada. Generalmente productores de bienes finales bajo subcontratación comercial 
-producen bienes linales para una empresa comercial del sector moderno- o bajo subcontratación productiva - producen partes para del producto tinal para una empresa manufacturera del sector modemo-; los productos de estos establecimientos no emiran directamente al mercado ya que por operar como "maquiladoras" enfrentan lo que podrlamos denominar demandas derivadas, es decir, demandas que dependen de las condiciones de mercado que enirentan los establecimientos "clientes" del sector moderno.

Evidentemente, la capacidad de "transformación ascendente" que proporciona el tipo de inserción es importante ya que puede establecerse una relación directa entre acumulación -ingresos-ventas-tamano y condiciones de mercado. Sin embargo, como los tamanos de los establecimientos- en trabajadores y capital pueden variar mucho al interior de cada uno de los sub-conjuntos anteriormente definidos, es claro que las ventajas de operar en un "nicho" dinámico podrán ser potenciadas o minimizadas por caracteristicas internas como la adecuación de la relación capital-trabajo.

Por olra parte, es plausible esperar que los criterios diferenciadores se presenlen, en alguna lorma, superpuestos entre si, deliniendo "asocialivamente" las potencialidades de Iranslormación estructural de los "establecimienlos" del sector informal urbano.

Utilizando to que podriamos denominar factores estructurales dominantes -internos y externos al establecimiento- se presenta en el cuadro 1 una clasificación ilustrativa de la heterogeneidad productiva de los establecimientos informales', según sus características predominantes. Estas caracteristicas determinan en gran medida la dinámica de sobrevivencia y la evolución-involución de los establecimientos.

De acuerdo a esta clasificación los subconjuntos con capacidad de translormación estruclural ascendente no son numerosos ya que las potencialidades de los establecimientos están restringidas por: las condiciones globales de la demanda, la adecuación tecnológica (en cantidad y calidad) y la actitud tradicional o cuasi-empresarial de los propielariosproductores. De esta manera, si se opera en un mercado amplio y competitivo, se cuenla con una dotación relativamente adecuada de capital, y una gestión guiada por una actitud cuasi-capitalista (búsqueda de ga-

1. Evidentemente esta tipificación no deline segmentos o sub-conjuntos "puros" y "excluyentes", ni tampoco prelende ser exhaustiva. Unicamente busca resaltar las caracterlsticas predominantes de los establecimientos que se diferencian por su inserción y su dotación capital-trabajo. 
nancias) se define un marco de posibilidades de transformación estructural, de generación de empleo y de expansión de ingresos, bastante amplio. En cambio, si se opera en "nichos" de mercado muy diferenciados y restringidos - localización espacial y clientelas-, con una dotación de capital deficiente, con tecnologlas arcaicas y una actitud mercantil tradicional signada por la lucha diaria por la subsistencia; se tendrlan más bien condiciones para el estancamiento o para desarrollar una dinámica involutiva.

\section{Cuadro Ne 1 \\ Helerogeneldad Productlva del Sector Informal según Inserclón Mercantll y Relaclón Capltal/Trabajo}

\begin{tabular}{|c|c|c|c|}
\hline$\frac{\text { Inserción mercantil }}{\text { Relación capitalurabajo }}$ & $\begin{array}{l}\text { Inserción } \\
\text { diferenciada }\end{array}$ & $\begin{array}{c}\text { Inserción } \\
\text { subordinada }\end{array}$ & $\begin{array}{l}\text { Inserción } \\
\text { competitiva }\end{array}$ \\
\hline $\begin{array}{l}\text { Deliciente y alternativa } \\
\text { tecnologica primitiva o } \\
\text { anticuada. }\end{array}$ & $\begin{array}{l}\text { Reproducción sim- } \\
\text { ple y/o restringida; } \\
\text { logica de subsisten- } \\
\text { cia y racionalidad } \\
\text { mercantil tradicio- } \\
\text { nal. }\end{array}$ & $\begin{array}{l}\text { Reproducción sim- } \\
\text { ple y logica de sub- } \\
\text { sistencia } \\
\text { (asalariados distra- } \\
\text { zados). }\end{array}$ & $\begin{array}{l}\text { Reproducción res- } \\
\text { tringida; logica de } \\
\text { subsistencia y ra- } \\
\text { cionalidad mer- } \\
\text { cantil tradicional. }\end{array}$ \\
\hline $\begin{array}{l}\text { Insuficiente y } \\
\text { altemativa } \\
\text { tecnológica apropiada. }\end{array}$ & $\begin{array}{l}\text { Acumulación defi- } \\
\text { ciente y racionali- } \\
\text { dad mercentil tradi- } \\
\text { cional. }\end{array}$ & $\begin{array}{l}\text { Acumulación res- } \\
\text { tringida; lógica de } \\
\text { independencia labo- } \\
\text { ral y actitud cuasi- } \\
\text { empresarial. }\end{array}$ & $\begin{array}{l}\text { Acumulación Deli- } \\
\text { ciente y lógica de } \\
\text { independencia la- } \\
\text { boral. }\end{array}$ \\
\hline $\begin{array}{l}\text { Adecuada y alternaliva } \\
\text { tecnológica apropiada y } \\
\text { compelitiva. }\end{array}$ & $\begin{array}{l}\text { Acumulación en } \\
\text { rango de restringida } \\
\text { a normal; logica in- } \\
\text { dependencia laboral } \\
\text { y recionalided mer- } \\
\text { cantil simple. }\end{array}$ & $\begin{array}{l}\text { Acumulación poten- } \\
\text { cial normal doble ló- } \\
\text { gica: independencia } \\
\text { laboral y evasión } \\
\text { regular social; ra- } \\
\text { cionalidad cuasi-ca- } \\
\text { pitalista. }\end{array}$ & $\begin{array}{l}\text { Acumulación po- } \\
\text { tencial normal: lo- } \\
\text { gica de indepen- } \\
\text { dencia laboral y } \\
\text { racionelidad cuasi- } \\
\text { capitalista. }\end{array}$ \\
\hline
\end{tabular}

Para un programa de apoyo crediticio al sector informal, es lundamental el establecer y asumir las diferencias exislentes enlre las actividades y los establecimienlos. En primer lugar, porque características de los establecimientos y de los propielarios-productores, así como también sus polencialidades de acumulación, van a definir diferenles respuestas al crédito en general y a las dilerentes modalidades que pueda asumir. En segundo lugar, es evidente a partir de lo anterior que algunos objelivos perseguidos con la lacilitación del acceso al crédito para los informales -expansión del empleo, aumento del producto, transfor- 
mación e inlegración del tejido productivo, etc. - no pueden ser alcanzados por las restricciones que pesan sobre la mayoría de los mlcro-establecimientos. FInalmente, porque la eficacia de un programa cualquiera queda grandemente comprometida si sus instrumentos y objetivos no se adecúan a la realidad sobre la que pretenden actuar.

\section{EVIDENCIA DE LA HETEROGENEIDAD EN EL SECTOR INFOR- MAL URBANO}

No es posible presentar dalos que sustenten las tipologlas expuestas en el acápite anterior debido a la inexistencia de encuestas o censos recientes que hayan recabado inlormación sobre las caracteríslicas y diferencias de los establecimientos productivos. Sin embargo, es posible lograr una aproximación de la heterogeneidad de los establecimientos inlormales- en cuanto a generación de excedenles, capacidad de acumulación y calidad de empleo- a partir de una reinterpretación de los dalos de las encuestas de hogares de propósitos múltiples.

La segmenlación básica de la estruclura ocupacional- en sector formal y sector informal- se realiza a partir de la pregunta (encuesta de mano de obra EH-F3) ¿cuántas personas en lolal laboran para la empresa, negocio o patrón con el cual trabaja? Todas aquellas personas que responden 1 persona o de 2 a 4 personas son clasificadas como ocupadas en el sector informal. Ahora bien, es claro que si el total de personas laborando es inferior a 2 se trata de establecimientos unipersonales inscrilos en la más pura lógica de subsistencia y que si el ocupado responde trabajar en un establecimiento de 2 a 4 personas. este último podría ser considerado una microempresa - estrictamente si existen relaciones salariales- con alguria capacidad de acumulación. De esla manera la primera aproximación a la heterogeneidad del sector informal puede obtenerse a partir de la respuestas a la pregunta anterior. Según la encuesla de hogares ene.-jun. 1990 (que será la fuenle de los datos que utilizaremos en este acápite) el rango posible de establecimientos de 2 a 4 personas sobre el total del sector informal oscilarla entre $22.4 \%$ (asumiendo 4 personas por establecimiento) y $36.6 \%$ (asumiendo 2 personas por establecimienlo), dicho de otra forma los "establecimientos" unipersonales de subsistencia constiluirian la.mayorla del sector.

Esle rasgo de la estruclura productiva se va a reflejar en la calidad de los pueslos de trabajo que se pueden generar en el sector (ver cuadro $N^{*} 2$ ), al limitar los puestos de trabajo y/o actividades de plena ocupación. 


\section{Cuadro 2 \\ Ocupados en el Sector Informal Urbano según \\ Condlción de Ocupación \\ (Porcentajes)}

\begin{tabular}{|c|c|c|c|c|c|c|c|c|}
\hline & Total & ndust. & Elecl. Gas y Agua & Construc. & Comercio & Transp. & Est. Finan. & Servic. \\
\hline \multirow{2}{*}{$\begin{array}{l}\text { Plena Ocupación } \\
\text { Sub-empleo }\end{array}$} & 42.0 & 42.8 & 54.5 & 22.8 & 42.1 & 56.3 & 53.8 & 43.2 \\
\hline & 58.0 & 57.2 & 45.5 & 77.2 & 57.9 & 43.7 & 46.2 & 56.8 \\
\hline
\end{tabular}

De acuerdo a los datos presentados, un poco más de la milad de los trabajadores del sector iniormal se encuentran subempleados, es decir que presentan productividades e ingresos insulicientes por su carencia de recursos complemenlarios a la mano de obra. La insuficiencia de ingresos (por autoremuneración o por salario) puede tener como causa directa una baja productividad o la sobremuneración competitiva, pero en ambos casos eslaría indicando que esos trabajadores laboran en establecimientos de "acumulación deficienle" o "reproducción simple deficienle".

Es de resallar la gran incidencia del subempleo en la industria ya que por las caracteristicas de las actividades en esla rama se presenlaria la mayor densidad de establecimientos y la subutilización reflejaria las limitaciones de acumulación y de integración productiva de las microempresas manufaclureras. En el comercio y los servicios pueden considerarse relativamente normales los niveles de subempleo encontrados ya que estas ramas son las que presentan aclividades con mayor lacilidad para la autocreación de ocupaciones, es decir para el desarrollo de inserciones laborales guiadas por la lógica de subsistencia. La rama con mayor precariedad laboral es la de la consirucción posiblemente porque la fuerza de trabajo intormal esta segmentada en subcontratistas (maestros de obra) y asalariados temporales; esta caracteristica limitaria grandemente la existencia de establecimientos con capacidad de acumulación. La capacidad de los financislas informales de apropiarse - via el crédito agiolista - de parte del excedente bruto generado en otras actividades informales explicaría sus mayores niveles de plena ocupación; para el transporte podrian incidir dos factores: el crecimiento urbano ha ampliado el mercado y debido a la alta inversión de entrada, ni los cuenlapropia ni los microempresarios responden a lógicas de subsistencia.

Una aproximación a la capacidad de generación de ingreso/excedente en el sector informal, puede obtenerse a partir del análisis de los 
datos correspondientes a la remuneración media mensual por categoria ocupacional (cuadro № 3).

\section{Cuadro $\mathbf{N}^{2} 3$}

Ocupados en el Sector Informal Urbano según

Categoria Ocupacional y Remuneraclón Mensual Medla

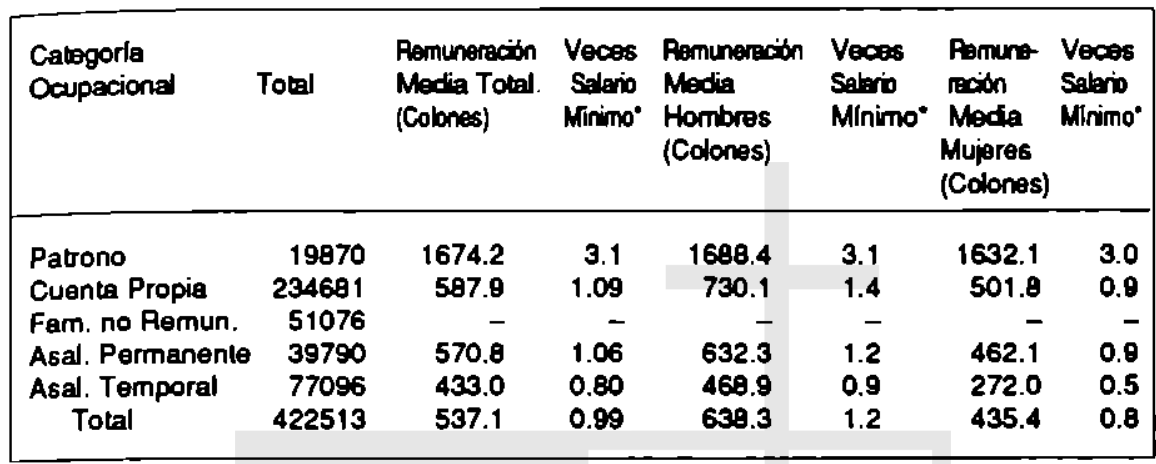

Fuente: Elaboración propia en base a datos Encuesta de Hogares de Propósitos Múltiples, MIPLAN, Enero-Junio 1990. Excluye servicio doméstico.

- El salario minimo durante el perlodo de recolección de datos de la encuesta fue de creación de datos en la encuesta hue de $\$ 540.00$.

Lo primero que llama la atención, es la baja capacidad de generación de excedenle que tiene el patrono promedio del sector iniormal, ya que sus ingresos únicamente equivalen a tres salarios mínimos. Más grave es la situación de los típicos productores de subsislencia (los cuentapropia), para los cuales su exigua dotación de medios de producción (o de (rabajo) no les permile obtener un ingreso mayor que el de un asalariado no calificado anulando de esla forma cualquier ingreso por la propiedad de los medios de Irabajo y reflejando una plausible subremuneración de su luerza de trabajo.

Las medias salariales indicarlan que la mayorla de las microempresas en donde se desarrollan relaciones salariales presentarían modalidades de acumulación deficiente (dos tercios de los asalariados obtendrian ingresos inferiores al salario mínimo) o presentarian acumulación restringida (limitadas utilidades y remuneraciones en el límite del salario mínimo legal). Esto es más evidente cuando se considera que las microempresas de las ramas que agrupan la mayor parte de los informales (industria y comercio) hacen un uso extendido de la fuerza de trabajo familiar no remunerada y de asalariados temporales. La situación 
de la trabajadora informal es bastante precaria, ya que exceptuando a las que se desempenan como patronos (únicamente $2.3 \%$ del total de trabajadoras) obtienen remuneraciones superiores al mínimo legal; el grueso de las mujeres ( $84.1 \%$ del total) Irabaja en calidad de cuenlapropia o como familiar no remunerado recibiendo ingresos inferiores al mínimo legal. En general, las remuneraciones medias indicarian que la capacidad global del sector inlormal para generar excedente es muy limitada y que las posibilidades de translormación estructural y de movilidad ascendente se limilarian a un grupo no muy grande eslablecimientos.

Anteriormente hemos señalado que la capacidad de crecimiento de los establecimientos individuales y el crecimiento "intensivo" (crecimiento en número y apropiación de cuotas de mercado) de los segmentos productivos informales es diferenciada por las condiciones particulares de las ramas en que operan -condiciones de compelencia, dinámica de la demanda, condiciones de transformación productiva tecnológica, elc.- de manera que ulilizando las diferencias de medias de remuneración entre las ramas produclivas podemos tener una aproximación a las diferencias de generación de excedentes y de capacidades de acumulación que presentan los eslablecimientos según en la rama que operan (cuadro № 4).

\section{Cuadro № 4 \\ Dlstrlbuclón de los Ocupados en el Sector Informal Urbano según Rama de Acilvidad y Tramo de Remuneración Mensual (Porcentajes)}

\begin{tabular}{|lrrrrrrrr|}
\hline $\begin{array}{c}\text { Tramos de } \\
\text { Remuneración } \\
\begin{array}{c}\text { Mensual } \\
\text { (Veces Salario } \\
\text { Mlnimo) }\end{array}\end{array}$ & Industria & $\begin{array}{c}\text { Elect.Gas } \\
\text { y Agua }\end{array}$ & $\begin{array}{c}\text { Construc- } \\
\text { ción }\end{array}$ & Comercio & $\begin{array}{c}\text { Trans- } \\
\text { porte }\end{array}$ & $\begin{array}{c}\text { Establecimiento } \\
\text { Finan- } \\
\text { ciero } \\
\text { Servi- } \\
\text { cios }\end{array}$ \\
\hline Ninguno & 14.8 & - & 2.2 & 15.0 & 1.0 & - & 3.1 \\
Menos de 0.9 & 50.9 & 45.5 & 48.8 & 44.4 & 25.5 & 34.8 & 61.2 \\
De 0.9 a 1.3 & 14.1 & - & 20.7 & 13.8 & 17.6 & 23.2 & 9.3 \\
De 1.3 a 1.9 & 10.0 & 54.5 & 21.8 & 12.3 & 21.5 & 16.4 & 14.9 \\
De 1.9 a 2.8 & 6.3 & - & 4.1 & 4.9 & 14.7 & 11.2 & 6.4 \\
De 2.8 a 4.6 & 2.7 & - & 1.6 & 6.5 & 15.9 & - & 3.1 \\
4.6 y más & 1.2 & - & 0.8 & 3.1 & 3.8 & 14.4 & 2.0 \\
\hline \multicolumn{1}{c}{ Tolal } & 100.0 & 100.00 & 100.0 & 100.0 & 100.0 & 100.0 & 100.0 \\
\hline
\end{tabular}

Fuente: Elaboración propia en base a datos Encuesta de Hogares de Propósitos Múltiples, MIPLAN, Enero-Junio 1990.

- Salario mínimo durante el perlodo de recolección de dalos de la encuesta fue de creación de datos en la encuesta lue de $\$ 540.00$. 
Los dalos indican una capacidad de generación de ingresos/excedentes, que es bastante desigual entre las diferentes ramas. La industria y los servicios presenla la mayor proporción de ocupados con remuneraciones inferiores al salario mínimo legal asi como también las menores proporciones - con la rama de la construcción- de ocupados con ingresos superiores a tres salarios minimos.

Por otra parte las ramas que concentrarian proporcionalmente a los establecimientos con mayor capacidad de generación de excedentes (mayor presencia de ocupados con mas de tres salarios mínimos) serian, en orden decreciente: establecimienlos financieros, transporte y comercio. Sin embargo, dado el bajo peso relalivo ocupacional de las ramas de establecimientos financieros y de transporte $(0.5 \%$ y $6.5 \%$ del tolal de ocupados del SIU estrictamente urbano), el total de ocupados con ingresos superiores a los tres salarios mínimos seria de aproximadamente $7.7 \%$, evidenciando la insuliciencia global del sector en cuanto a generación y retención de excedentes.

Finalmente, para corroborar la baja capacidad de acumulación y el predominio de las lógicas de subsistencia entre los propietarios-productores del sector informal se pueden ulilizar los datos del cuadro $N^{2} 5$ que presenta una clasificación de patronos y de cuentapropias según la condición de pobreza del hogar al que perlenecen.

\section{Cuadro $\mathbf{N}^{2} 5$}

Microempresarlos del Sector Informal Ubano según

Condlcion de Pobreza del Hogar* (Porcentajes)

\begin{tabular}{|l|c|c|c|c|c|}
\cline { 2 - 6 } \multicolumn{1}{c|}{} & Total & $\begin{array}{c}\text { Pobreza } \\
\text { Crónica }\end{array}$ & $\begin{array}{c}\text { Pobreza } \\
\text { Peciente }\end{array}$ & $\begin{array}{c}\text { Pobreza } \\
\text { Inercial }\end{array}$ & $\begin{array}{c}\text { Integrados } \\
\text { Socialmente }\end{array}$ \\
\hline Total Patronos & 100.0 & 31.1 & 5.7 & 33.8 & 29.4 \\
Total cuenta propia & 100.0 & 59.5 & 0.1 & 19.8 & 12.6 \\
\hline
\end{tabular}

Fuente: Elaboración propia, en base datos inéditos de la Encuesta de Hogares de Propósilos Múltiples, MIPLAN, Enero-Junio 1990. Excluye servicio doméstico.

- Agrupa los grupos prinicpales de la huerza de trabajo familiar (Jefes de hogar, cónyuges e hijos mayores de 10 años).

El supuesto básico adoptado para utilizar como "proxy" de la capacidad adecuada de generación de excedentes a la condición de pobreza de los hogares, es la idea de que la propiedad de un negocio próspero garantiza un nivel de vida aceptable, en cambio la propiedad -o 
inserción laboral de un "negocio" precario y estancado no generaria ingresos suficientes para la cobertura de las necesidades básicas.

Los datos nos muestran diferencias radicales entre los dos grupos de produclores propielarios, por una parte tenemos que entre los cuentapropia (que constituyen el $55.5 \%$ del total de mlembros del SIU). apenas la décima parle pertenece a hogares que pueden considerarse integrados socialmente (sus ingresos familiares son superiores a la línea de pobreza y además no presentan insatisfacción en materia de acceso a servicios básico ni tampoco padecen de hacinamiento); en cambio la mayoría de los pertenecientes a esta categorla ocupacional padecen una pobreza crónica, es decir que pertenecen a hogares con largo tiempo de pobreza y allas posibilidades de transmitir o heredar pobreza²; por otra parte, es de hace notar que aproximadamente una quinta parle adicional sutre de carencias en materia de las necesidades básicas vinculadas al habitat familiar (pobreza inercial).

En relación a la calegoría de patronos -que por definición serían microempresarios-, se observa una mayor representación en la calegoria de hogares integrados socialmente, sin embargo, es necesario senalar que dicha proporción es similar a la encontrada para los jefes de hogar asalariados del sector moderno e inferior a la de los jeles de hogar asalariados del sector público y de los jefes de hogar que se desempenan como cuentapropia en el sector moderno (ver Briones, 1992). Los dalos además muestran que aproximadamente un tercio de los patronos pertenece a hogares - pobreza crónica- cuyo ingreso promedio per-cápila oscilaba entre 0.3 y 0.7 de la línea de pobreza relaliva, (Briones, 1992) y que olro tercio podía ser considerado como pobres por sus carencias en materia de necesidades básicas insalisfechas.

En sinlesis la evidencia presentada nos muestra la existencia de un allo grado de heterogeneidad y de marcadas diferencias en cuanto a las posibilidades y de translormación producliva entre los establecimientos y trabajadores del sector inlormal. Esta heterogeneidad obliga necesariamente a asumir el desafío de disenar programas diferenciados -especílicos- y a desarrollar un mayor esfuerzo de coordinación en un plan de apoyo de múlliples objetivos.

\section{IMPORTANCIA DEL APOYO FINANCIERO AL SECTOR INFOR- MAL URBANO}

Las unidades del SIU, no parecen tener problemas para obtener "ca-

2. Para ahondar en categorias de pobreza, ver Briones (1992). 
pital" para iniciar su negocio o para autocrear su empleo -algunos autores consideran que esta relativa lacilidad contribuye a sobredimensionar el sector y de alguna forma a disminuir los ingresos medios-; este "capital" es obtenido —por carencia de historia crediticia y credenciales socioprolesionales o de proyectos- fuera del sistema formal de financiamiento. En general, las luentes originales son redes familiares, fondos propios y financiamiento informal (ver cuadro $N^{2} 6$ ) y por tanto en la mayoría de casos es escaso o insuliciente para generar un adecuado llujo de ingresos o para permitir la expansión del "establecimiento".

\section{Cuadro $N^{2} 6$ \\ Microempresas del Sector Informal Ubano por fuente principal para Iniclar el negoclo}

\begin{tabular}{|c|c|c|c|c|c|c|}
\hline \multirow{2}{*}{$\begin{array}{c}\text { Rama } \\
\text { de } \\
\text { Actividad } \\
\text { Económica }\end{array}$} & \multirow{2}{*}{ Total } & \multicolumn{5}{|c|}{ Fuente principal de Financiamiento } \\
\hline & & $\begin{array}{l}\text { Institución } \\
\text { Financiera }\end{array}$ & $\begin{array}{l}\text { Préstamo de } \\
\text { Cooperativas }\end{array}$ & $\begin{array}{l}\text { Préstamo de } \\
\text { Famil. y/o amigo }\end{array}$ & $\begin{array}{c}\text { Presta- } \\
\text { mista }\end{array}$ & $\begin{array}{c}\text { Ahorros } \\
\text { Propios Otros }\end{array}$ \\
\hline $\begin{array}{l}\text { Microempr. } \\
\text { Porcentajes }\end{array}$ & $\begin{array}{c}203 \\
100.00\end{array}$ & $\begin{array}{c}25 \\
11.74\end{array}$ & - & $\begin{array}{c}26 \\
12.21\end{array}$ & $\begin{array}{c}11 \\
5.16\end{array}$ & $\begin{array}{cc}147 & 4 \\
69.01 & 1.88\end{array}$ \\
\hline
\end{tabular}

Fuente: Encuesta de Hogares de Propósitos Múltiples. Ministerio de Planificación Septiembre-Diciembre 1986.

Como muestran los resultados de una pequena encuesta de eslablecimienlos realizada por el Miplan en el área metropolitana de San Salvador (1986), la principal fuente de financiamiento de las microempresas son los ahorros propios (69\%) seguida de préstamos de tamiliares y de préstamos de instituciones linancieras formales. Eslos resullados son similares a los obtenidos en otra pequena muestra de microempresas (Alvarez, 1988) que sefialan también a los ahorros $(74.2 \%)$ como "capital" semilla.

Esta característica básica del tinanciamiento inicial de los establecimienlos informales sugeriría tres aspectos a considerar: en primer lugar, que por la relativa facilidad de acceso al capilal inicial para desarrollar actividades inlormales y por la diticultad de evaluar la capacidad productiva de los potenciales demandantes de crédito (y su capacidad para relornar el préslamo), el olorgamiento de préstamos de inicio no debería constituirse en un componenle de un programa de apoyo financiero del seclor. En segundo lugar, siendo los ahorros la fuente principal del financiamiento de creación del establecimiento, puede esperarse que 
entre las diferentes técnicas, los productores tenderán a escoger aquellas menos intensivas en capital y por tanto entrentaran dificultades para sostener una dinámica de acumulación. En tercer lugar, de lo amterior lambién se derivaría que podrían existir inadecuaciones entre diferentes formas de capital que afectarían la oblención de mayores productividades.

En relación al segundo aspecto, se puede observar en el siguiente cuadro - que presenta la relación capital trabajo- que en general las microempresas -que son los establecimientos de mayor tamano del SIU- presentan muy bajos niveles de capital fijo. El promedio era de aproximadamente US\$1000 por trabajador y el $60.0 \%$ se siluaba abajo de los US\$550. Por otra parte, es de resaltar que el promedio de las microempresas manufactureras era de US\$758 y más de la mitad $(52.8 \%)$ presentaban una relación inlerior a los US\$370. Como podía esperarse la mayor relación capilal/trabajo se presentaba en la rama de

\section{Cuadro NN$^{2} 7$}

Microempresas por nlvel de relación capltal-trabajo (K/L) según rama de actividad economica

\begin{tabular}{|c|c|c|c|c|c|c|c|c|c|c|c|c|}
\hline \multirow{2}{*}{$\begin{array}{c}\text { Pama } \\
\text { An } \\
\text { Actividad } \\
\text { Econdinica }\end{array}$} & \multirow{2}{*}{$\begin{array}{l}\text { Prantado } \\
\text { Ralacion } \\
\text { (WLI)USS }\end{array}$} & \multirow{2}{*}{ Tolal } & \multicolumn{10}{|c|}{ Nivel de Relación Capital Trabajo } \\
\hline & & & $\begin{array}{l}111.1 \mathrm{y} \\
\text { Monos }\end{array}$ & $\begin{array}{c}111.3 \mathrm{a} \\
1 \mathrm{eS.2}\end{array}$ & $\begin{array}{c}165.4 \mathrm{a} \\
370.4\end{array}$ & $\begin{array}{l}3705 \text { a } \\
460.0\end{array}$ & $\begin{array}{c}463.1 \text { a } \\
555.5\end{array}$ & $\begin{array}{c}556.7 \mathrm{a} \\
740.7\end{array}$ & $\begin{array}{l}741.0 \mathrm{a} \\
1111.1\end{array}$ & $\begin{array}{l}1111.3 \\
1481.5\end{array}$ & $\begin{array}{l}21401.6 \\
2777.8\end{array}$ & $\begin{array}{l}\text { más de } \\
2777.8\end{array}$ \\
\hline $\begin{array}{l}\text { Tota } \\
\text { X Fila } \\
\text { X Colums }\end{array}$ & $\begin{array}{c}1.003 .5 \\
- \\
-\end{array}$ & $\begin{array}{c}213 \\
100.00 \\
100.00\end{array}$ & $\begin{array}{c}34 \\
15.96 \\
100.00\end{array}$ & $\begin{array}{c}22 \\
10.33 \\
100.00\end{array}$ & $\begin{array}{c}31 \\
14.55 \\
100.00\end{array}$ & $\begin{array}{c}16 \\
7.51 \\
100.00\end{array}$ & $\begin{array}{c}25 \\
11.74 \\
100.00\end{array}$ & $\begin{array}{c}19 \\
8.92 \\
100.00\end{array}$ & $\begin{array}{c}24 \\
11.27 \\
100.00\end{array}$ & $\begin{array}{c}11 \\
5.16 \\
100.00\end{array}$ & $\begin{array}{c}15 \\
7.04 \\
100.00\end{array}$ & $\begin{array}{c}6 \\
7.51 \\
100.00\end{array}$ \\
\hline $\begin{array}{l}\text { Indusuia } \\
\text { \% Fils } \\
\text { \% Columns }\end{array}$ & $\begin{array}{c}758.2 \\
- \\
-\end{array}$ & $\begin{array}{c}53.00 \\
100.00 \\
24.88\end{array}$ & $\begin{array}{c}\theta \\
16.88 \\
26.47\end{array}$ & $\begin{array}{c}\theta \\
16.98 \\
40.91\end{array}$ & $\begin{array}{c}10 \\
18.87 \\
32.26\end{array}$ & $\begin{array}{c}7.55 \\
25.00\end{array}$ & $\begin{array}{c}8 \\
15.00 \\
32.00\end{array}$ & $\begin{array}{c}5 \\
9.43 \\
26.32\end{array}$ & $\begin{array}{c}1 \\
1.89 \\
4.17\end{array}$ & $\begin{array}{c}1 \\
1.89 \\
9.00\end{array}$ & $\begin{array}{c}3 \\
5.66 \\
20.00\end{array}$ & $\begin{array}{c}3 \\
5.66 \\
18.75\end{array}$ \\
\hline $\begin{array}{l}\text { Comprcio } \\
\text { * Fila } \\
\text { \% Columna }\end{array}$ & $\begin{array}{c}1.029 .0 \\
- \\
-\end{array}$ & $\begin{array}{c}121 \\
100.00 \\
56.81\end{array}$ & $\begin{array}{c}22 \\
18.18 \\
64.71\end{array}$ & $\begin{array}{c}10 \\
8.26 \\
45.45\end{array}$ & $\begin{array}{c}12 \\
9.92 \\
38.71\end{array}$ & $\begin{array}{c}10 \\
8.26 \\
62.50\end{array}$ & $\begin{array}{c}13 \\
10.74 \\
52.00\end{array}$ & $\begin{array}{c}12 \\
9.52 \\
63.16\end{array}$ & $\begin{array}{c}15 \\
12.40 \\
62.50\end{array}$ & $\begin{array}{c}9 \\
7.44 \\
81.82\end{array}$ & $\begin{array}{c}10 \\
8.26 \\
66.67\end{array}$ & $\begin{array}{c}\theta \\
6.61 \\
50.00\end{array}$ \\
\hline $\begin{array}{l}\text { Transpor. y } \\
\text { Comunic. } \\
\text { × Flla } \\
\text { \% Columna }\end{array}$ & $\begin{array}{c}2360.7 \\
- \\
-\end{array}$ & $\begin{array}{c}B \\
100.00 \\
3.76\end{array}$ & $\begin{array}{l}- \\
-\end{array}$ & $\begin{array}{c}1 \\
12.50 \\
1.55\end{array}$ & $\begin{array}{c}1 \\
12.50 \\
3.23\end{array}$ & $\begin{array}{c}1 \\
12.50 \\
6.25\end{array}$ & $\overline{-}$ & $\begin{array}{c}1 \\
12.50 \\
5.26\end{array}$ & $\begin{array}{c}1 \\
12.50 \\
4.17\end{array}$ & $\begin{array}{c}1 \\
12.50 \\
9.09\end{array}$ & I & $\begin{array}{c}2 \\
25.00 \\
12.50\end{array}$ \\
\hline $\begin{array}{l}\text { Eslablecim. } \\
\text { Finandiero } \\
\text { \% Fla } \\
\text { \% Columna }\end{array}$ & $\begin{array}{c}606.9 \\
- \\
-\end{array}$ & $\begin{array}{c}6 \\
100.00 \\
2.08\end{array}$ & $\begin{array}{l}- \\
-\end{array}$ & $\begin{array}{l}- \\
-\end{array}$ & $\begin{array}{c}3 \\
50.00 \\
9.88\end{array}$ & - & $\begin{array}{l}- \\
-\end{array}$ & $\begin{array}{l}- \\
-\end{array}$ & $\begin{array}{c}3 \\
50.00 \\
12.50\end{array}$ & - & 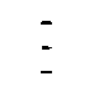 & $\begin{array}{l}- \\
-\end{array}$ \\
\hline $\begin{array}{l}\text { Servidor } \\
\text { \% Fila } \\
\text { \% Columna }\end{array}$ & $\begin{array}{c}1059.7 \\
- \\
-\end{array}$ & $\begin{array}{c}25 \\
100.00 \\
11.74\end{array}$ & $\begin{array}{c}3 \\
12.50 \\
8.82\end{array}$ & $\begin{array}{c}2 \\
8.00 \\
9.09\end{array}$ & $\begin{array}{c}5 \\
20.00 \\
16.13\end{array}$ & $\begin{array}{c}1 \\
1.00 \\
6.25\end{array}$ & $\begin{array}{c}1 \\
16.00 \\
16.00\end{array}$ & $\begin{array}{c}1 \\
1.00 \\
5.26\end{array}$ & $\begin{array}{c}4 \\
16.00 \\
16.67\end{array}$ & - & $\begin{array}{c}2 \\
8.00 \\
13.39\end{array}$ & $\begin{array}{c}3 \\
12.00 \\
18.75\end{array}$ \\
\hline
\end{tabular}

Fuente: Encuesta de Hogares de Propósitos Múltiples. MIPLAN. Septiembre-Diciembre 1986

Capital lijo/Tolal de personal en la Microempresa

US\$ $=5.4$

Noviembre 86

Mercado Paralelo

(Fuente: Boletín Económico BCR № 8. Noviembre 88). 
transporte y el comerclo establecido (pequehos almacenes, llendas, puestos fijos del mercado, elc.) presentaba una relación aceplable- y posiblemente bastante competitiva - para los "nichos" de mercado en que actuan.

Si comparamos los resullados del cuadro anterior con las relaciones capitaltrabajo obtenidas para el sub-sector manulacturero en último censo de establecimientos (1978) queda de manitiesto el problema de la inadecuación de capilal que hemos sehalado anteriormente. De acuerdo al censo, el promedio tolal de todos los establecimientos de más de 5 empleados era de US\$7970, siendo el de las pequehas y de las medianas -las más próximas tecnológicamente- de US\$2581 y de US\$5157 respectivamente; es decir entre 3.4 y 6.8 veces más que la relación encontrada las microempresas industriales.

En la gran mayoria de casos de microempresas de servicios e industriales se presenta una inadecuación en la dotación de capilal (tijo y de (rabajo) que puede manifeslarse en inadecuación de calidad (equipos usados y equipos "hechizos" o "caseros") 0 insuficiencia relativa en relación a la capacidad laboral de la mano de obra.

Esta insuficiencia es posiblemente el principal problema para la mayoría de productores del SIU -tomando en cuenta que solo una pequeha proporción tiene capacidad de Iransformación-, ya que en razón de que la opción tecnológica (capital tijo) adoptada es posiblemente la unica posible y por tanto, si no hay cambios radicales en el lamano de los "nichos" de mercado, se convierte en un dato, serian las limitaciones en capital de trabajo el principal obstáculo para expandir la producción y las venlas.

Al respecto, habria que sefialar que de acuerdo a la encuesta del Miplan (1986). los principales problemas de las microempresas encuestadas eran: falta de mercados $(31.9 \%)$, falla de capilal de trabajo $(23.5 \%)$ y local inadecuado (21.1\%). Ora encuesla (Alvarez, 1988) sehalaba que los dos principales problemas entrentados por los microempresarios tradicionales eran: saturación microempresarial de mercado (38.0\%) y los intereses elevados y la falta de acceso a crédito adecuado $(47.0 \%)$.

En esta línea, H. López (1990) después de resaltar que los ingresos $y$ las ventas dependen fundamentalmente de las condiciones de demanda que entrentan los microproductores, hace énfasis en la importancia que tiene el acceder oportuna y adecuadamente a los préstamos de capital de trabajo.

Cuando la demanda está en expansión también se expanden las 
necesidades de capital de trabajo para todos los productores -y los informales no son la excepción-y es evidente que aquellos que no logren acceder al credito enfrentaran serlos problemas para conservar su "cuota" del mercado en expansión.

Es claro que la expansión de la producciónventas, dependerá del grado de subutilización de la capacidad fija instalada (activos tijos y mano de obra familiar y/permanenle) y que el papel fundamental del crédito de capilal de trabajo serla el evitar que la subutilización subsista a pesar de las mejores condiciones del entorno externo. Este tipo tinanclamlento puede disminulr la subocupaclón de la mano de obra permanente, Incrementar el uso de Insumos productlvos o de la mano de obra temporal, permittendo de esta forma alcanzar la expansión de escala de producclón y los maximos niveles posibles de productlvidad.

Incluso los crédilos para capilal de trabajo con plazos normales (2 a 3 anos de plazo) pueden ayudar a expandir la capacidad rija instalada cuando -por las opciones tecnológicas de producción- pueden hacerse adiciones paulatinas en la escala de producción a través de la adición de herramientas y mano de obra en procesos productivos de cooperación simple (multiplicación proporcional de la escala, la capacidad y la producción) $)^{3}$.

Evidentemente, si por las tecnologías existentes, los aumentos en la escala de producción solo pueden darse por saltos tecnológicos, entonces el papel del crédito se vuelve fundamental (conjuntamente con las características individuales de los microproductores) para la transformación productiva del SIU y para posibilitar su capacidad de vincularse o competir con las estructuras productivas modernas.

Ahora bien, a los problemas anteriores -escaso capital inicial $\theta$ insuficiente capital de trabajo- se suma la restricción a los recursos del sistema financiero formal que configura de esta forma un entorno externo hostil para la expansión. En general, los productores más pequenos (microempresarios tradicionales y trabajadores por cuenla propia) enirentan mayores reslricciones por parte del sistema tinanciero formal por las razones siguientes:

3. El acceso al crédito para capilal de trabajo puede - aún con demanda constante- posibilitar para ciertos productores un aumento de su producción y sus ventas en función del grado de subutilización de la capacidad instalada y de la existencia de condiciones particulares de mercado (preferencias, localización espacial, etc.). 
1. Desconflanza en la supervivencla y solvencla de los microestablecimlentos. Para los intermediarios financieros, eslos microestablecimienlos presentan una elevada mortalidad e insolvencia (o bien una extrema movilidad del usuario) que los encuadra como clientes caros y de alto riesgo. Además existe la creencia de las causas de los problemas anteriores son inherentes a los establecimientos del sector informal. Es común, escuchar en estos medios que esle tipo de carteras de crédito son de baja rentabilidad y de allo riesgo; que la falta de educación (formal y crediticia) de este calegoría de usuarios eleva los coslos de transacción para las instituciones y que la alta heterogeneidad de los microusuarios aumenta lodos los costos de administración y conlrol de los programas de crédito.

2. La fllosofla bancarla de recuperaclón de préstamos. La racionalidad bancaria para evaluar la capacidad de retorno de los préstamos privilegia la cobertura por garantias reales -de preferencia hipotecaria o prendaria- que tengan, en su opinión, un adecuado grado de liquidez. En este sentido, se privilegia a aquellas microempresas más establecidas y con mayores flujos de caja ${ }^{4}$.

El problema del financiamiento para el SIU es que en el sector financiero formal no existen melodologías para adecuar la oferta de recursos a la pequeńa escala de los microproduclores ni capacidad para desarrollar una evaluación de la capacidad empresarial del solicitante y de su capacidad de obtener ingresos uficientes para retornar el préstamo.

El actual esquema institucional de apoyo esta basado en dos programas que cuentan con el respaldo del Banco Central: 1) Programa de Micro y Pequeña Empresa y 2) Fondo de Garantía de Crédito para la Micro y la Pequena Empresa.

El enfoque de estos programas es tradicional y tiende a excluir sistemálicamenle a la mayoria de las unidades del sector informal, ya que los mecanismos de calificación de solicitudes y garantias- y los conceptos utilizados para definir a la microempresa y a la pequeña empresa- permiten a las instiluciones financieras inlermedias "descremar" a los sujetos de crédilo escogiendo solamente aquellos "bancariamente" renlables eliminando las lípicas unidades de subsistencia.

4. No obstante lo anlerior es necesario señalar que como consecuencia de la alta migración y de la baja liquidez de los pequeños aclivos, algunas instituciones prefieren como garantla un historial positivo del demandante como usuario de los servicios de la institución y la existencia de recursos propios depositados como base de una "compensación" para posibles moras. 
Al definir a la microempresa como unidades cuyos activos no exceden los 100.000 colones y al delegar la calificación de solicitudes en los intermediarios, se permile que los bancos seleccionen activamente bajo los criterios tradicionales- a los usuarios del programa.

Otro elemenlo que actúa en contra de extender la cobertura del programa a la mayoría de los informales es el diseno que uniformiza dos sujelos de crédito -pequena empresa y microempresa- diferenles y permite a los intermediarios financieros movilizar recursos y cumplir metas de asignación de recursos segmentando selectivamente a los usuarios ${ }^{5}$.

Los principales logros de estos programas -iniciados en dic. de 1990 - pueden apreciarse en el cuadro $N^{2} 8$ que resume la movilización de recursos para la pequena y la microempresa en 1991 y 1992.

\section{Cuadro $\mathrm{N}^{2} 8$}

\section{Creditos y Garantlas a la Pequefía y Microempresa por el Sistema Financiero Oflclal}

\begin{tabular}{|l|rr|rr|}
\hline Inslituciones & \multicolumn{2}{|c|}{$\begin{array}{c}1991 \\
\text { (Colones) } \\
\text { Crédilos Garantias }\end{array}$} & $\begin{array}{c}\text { 1992 } \\
\text { (Colones) } \\
\text { Crédilos Garanlias }\end{array}$ \\
\hline Bancos Comerciales & 305.5 & 13.9 & 609.1 & 34.8 \\
Inst. Oficiales & 225.2 & 7.4 & 271.1 & 18.7 \\
- BFA & 43.4 & - & 40.6 & - \\
- FIGAPE & 24.9 & - & 32.5 & - \\
- FEDECREDITO & 156.9 & - & 198.0 & - \\
\hline Tolal & & & & \\
\hline
\end{tabular}

Fuente: BCR; LPG 22 Febrero 1993 y LPG 17 Julio 1992.

Los resultados nos sugieren que el financiamiento ha sido satisfactorio, sobre todo por el significativo aumenlo en la movilización de recursos desde los bancos comerciales. Sin embargo, es necesario relativizar

5. Como ejemplo de las asignaciones crediticias resultantes de programas no especializados en una población "meta" especifica puede señalarse que en abril de 1992 la cartera de micro y pequeña empresa del Banco Agricola Comercial —uno de los bancos comerciales con mayor experiencia- ascendía a 262 millones de colones con 28725 créditos y el $89 \%$ correspondian a la categoría de pequeño empresario. (Iniorme misión Gob. de Holanda). 
estos resultados - sobre todo en relación al sector informal- sefialando:

- La existencia de una considerable concentración de los créditos aprobados por la banca comercial, ya que el Bco. Cuscallán y el Bco. Agricola Comercial movilizaron el $66.4 \%$ y el $76.2 \%$ de los préstamos en 1991 y 1992. Lo anterior sugiere que el sistema en su conjunto responde muy lentamente a este segmento del mercado, aun con el apoyo del BCR.

- De acuerdo a diferentes informes del Departamento de Crédilo Privado del BCR, el promedio de los crédilos olorgados por los bancos comerciales osciló entre, mayo y agosto de 1992, entre 65.0 y 70.0 miles por lo que podia suponerse un allo grado de concentración de la cartera en la pequefía empresa.

- La idea anterior puede ser respaldada con la inlormación desglosada correspondienle a los meses de enero-abril de 1992. De 2698 crédilos aprobados por la banca comercial, el $61.8 \%$ correspondian a la pequena empresa -enlre 100.000 y 750.000 colones de aclivos $-y$ del monto total de recursos asignados (173.2 millones) solamente el $13.1 \%$ tue asignado a la microempresa.

Por otra parte, el préstamo promedio de la banca comercial era de 90.2 miles para la pequefia empresa y de 21.8 miles para la microempresa, lo que evidenciaba una alta selectividad de los sujetos de crédito y la exclusión de la "base" de la estruclura empresarial del sector informal.

- Oro dato que es necesario relalivizar - para evaluar la magnitud verdadera del esfuerzo realizado- es el correspondiente al crédito otorgado por las instituciones oficiales. Si se excluye el Programa de Crédito Popular de Fedecrédito 6 , se tiene que —para agoslo 1992el total de créditos aprobados se disminuiría en $95.3 \%$ (de 62701 a 5934 ) y los montos olorgados en $63.3 \%$ (de 169.8 a 62.3 millones). Sin embargo es preciso sefialar que estas instituciones muestran más apertura hacia la microempresa, ya que de 1444 crédilos aprobados para el periodo ene.-abril 1992 el $95.6 \%$ eran para microempresarios con una media de 13.0 miles.

6. Es necesario no tomar en cuenta este programa porque: exisle desde la lundación de Fedecrédito, es autofinanciado y además los créditos tienen una duración de dos meses por lo que el monto real de recursos comprometidos debería ser dividido entre seis. 
Otro elemento nuevo en la política gubernamental hacia la pequefia y la microempresa, es la creación de una Comisión Nacional para coordinar las actividades de apoyo a la microempresa. Esta comisión es creada por el decreto ejeculivo $N^{2} 39$ en mayo de 1991 integrándola el vicepresidente de la República, los ministros de Planificación y Economía, los Presidenles del Banco Central y de FIGAPE, dos representantes de ANEP y dos representantes de las gremiales de la micro y pequefia empresa.

Esta comisión liene bajo su cargo una comisión técnica y una comisión ejecutiva que se encargan respectivamente de la coordinación de las polílicas propuestas por la Comisión Nacional y de asegurar su ejecución, a través de la planeación, organización y control de las áreas de trabajo de las diferentes inslituciones involucradas en las aclividades de apoyo y tortalecimienlo a la microempresa.

Este modelo inslitucional -posiblemente por su misma forma de Comisión de alto nivel- no ha sido muy operativo en el cumplimiento de sus dos grandes funciones: diseño y coordinación de políticas especíicas para los pequenos productores de bienes y servicios.

La comisión ejecutiva del programa es juramentada hasta el 6 de ocl. de 1992, es decir año y medio después de la creación de la Comisión Nacional y la creación de una Comisión Consultiva integrada por representantes de las gremiales microempresariales, es retrasada hasla noviembre 1992. Por otra parte esta Comisión ha tenido dificultades para captar recursos financieros que le permita disefiar nuevos programas y su principal logro ha sido el programa "San Miguel Ya" financia - con londos de la Secretaria de Reconsirucción-a 200 microempresarios de los municipios de Sesori, Ciudad Barrios y San Luis de la Reina en el departamento de San Miguel.

En resumen, las principales lecciones que pueden extraerse de la caracterización global del sector informal salvadoreno $-y$ de los antecedentes sobre el apoyo olicial- al sector son las siguientes:

- Los establecimientos presentan desiguales capacidades y desiguales oportunidades, por tanto un programa de apoyo crediticlo maslvo al sector Informal no puede ni debe ser homogéneo ni unlformizante.

-En general, los fines de los programas deberían de ser menos ambiciosos y restringirse -de acuerdo al tipo de establecimiento o población meta- a tres grandes objetlvos: primeramente, elevar los ingresos de los trabajadores informales pobres mediante una sustitución del crédito inlormal (usurero) como fuente de financiamiento del capilal 
de trabajo de los microproductores. De lo que se trata en este caso es de internalizar los mayores ingresos (o las "utilidades") derivadas de la expansión de las ventas que se obtendría después del incremento de los recursos de operación. Es decir, se Irataría no solamente de facilitar los medio para responder a las oportunidades de expansión sino también de evitar la transferencia de ingresos vía los tipos de interés. EI segundo objetlvo, debería de ser el de disminuir los niveles de subutilización dentro del SIU a través de la elevación de la calidad de los puestos de Irabajo. Esto implica que a través del crédito no debe buscarse extender el SIU -esto lo hacen espontáneamente los mismos microproduclores - sino mas bien garantizar el complemento de capilal necesario para elevar los flujos de ingreso por mayor ulilización de la capacidad fija inslalada. FInalmente, y derivándose del anterior objetivo, se buscaría translormar productiva y organizativamente al segmento con capacidad de acumulación en el entendido que la finalidad de estos programas no es la de "elemizar" las lógicas de subsistencia.

-El crédilo no debe ser visto como la panacea, sino como un mecanismo de apoyo necesarlo pero no suflelente. Como insirumento de apoyo a la expansión no puede contrarrestar las tendencias de un mercado en contracción, ni tampoco las restricciones resultantes de la saluración microempresarial de los nichos de mercado, así como tampoco puede suplir la ausencia de faclores intemos favorables a la transformación. En este sentido los objetivo de los programas crediticios deben ser delinidos realistamente y considerando las restricciones que pesan sobre los diferenles grupos objelivos. Igualmente su diseho inslitucional debe de considerar la complementaridad con otro lipo de apoyos al crecimiento/transiormación del sector o de los diferentes segmentos que lo conlorman.

De acuerdo a lo anterior un PROGRAMA DESEABLE DE APOYO AL SECTOR INFORMAL debe de ser lo suficientemente abiento y flexible y en la búsqueda de estos criterios pueden considerarse como premisas básicas:

- El insirumento más adecuado podría ser un plan mulliprograma con una inslancia instilucional integradora y coordinadora una especie de Fondo de Inversiones Produclivas con amplias lacullades en cuanlo a la caplación y administración de recursos a cualquier título y con una aulonomia administrativa que le permita un régimen propio en materia de contrataciones y compras de bienes y servicios-que delegaría la ejecución en unidades/instituciones que gozarian de un alto grado de autonomía. 
Estos programas específicos deberian ser disefhados en función ex. clusiva de la población objelivo que se busca atender, de los objetivos a alcanzar en materia de transformación de la situación inicial sobre la que se prende actuar y de las diterentes instancias de la sociedad civil que pueden ejercer eficientemente funciones de apoyo.

- Las políticas de apoyo pueden variar según la rama y los tipos de microempresa, por lo que se vuelve fundamental que la inslancia institucional desarrolle investigaciones para determinar las condiciones del entorno y las potencialidades de los conjunlos de microempresas que se pretende atender.

- En materia de crédito pueden establecerse dos líneas básicas: la primera, seria de funcionamiento o de "capital de trabajo" destinada a la mayoría de las unidades del sector inlormal con el objeto de estabilizar o mejorar sus ingresos y la segunda sería una línea de "créditos de desarrollo" para propiciar la Iranstormación productiva de las unidades con mayor potencial. La instancia encargada del programa se encargaria de segmentar a los usuarios de acuerdo a su potencial y a la estrategia global de desarrollo productivo.

- La instancia encargada del Programa deberia desarrollar diferentes programas de apoyo y descentralizar su ejecución. El programa podria subdividirse en sub-áreas de crédilo, capacitación, apoyo tecnológico, apoyo jurídico y apoyo de comercialización pero integrándolos alrededor del programa crediticio y otorgando autonomia operativa a los ejecutores responsables de los diferentes programas especílicos que se diseñen según la población mela.

- Un aspecto clave para ampliar la cobertura y tener incidencia como programa produclivo anti-pobreza es el desarrollo de diversas modalidades de créditos solidarios, comunitarios y autogestionarios. También es importanle descentralizar regionalmente la asignación de los recursos globales y apoyar las iniciativas locales de desarrollo?.

- Es necesario desarrollar polílicas instilucionales de acompafiamienlo destinadas a modificar el entorno -al máximo posible- en que

7. Una experiencia a analizar con el objeto de extraer lecciones para la sislematización de un programa crediticio de amplia cobertura seria el programa de apoyo crediticio de PRODERE-ELS, que maneje descentralizadamente extensionismo crediticio, londos de garantía, llneas de crédito, Iondo rotativo comunal, crédito aulogestionario local y fondo de garantías para cooperativas; con instituciones tan dilerentes como FIGAPE, el BFA, el BCO. HIPOTECARIO, FINCA (banco comunales), CORDES/comites financieros comunitarios locales y AMPES. 
actúan las microempresas del sector informal, porque no tiene sentido expandir el crédito sino se cambian las restricciones estructurales que impiden una mayor generación - y apropiación interna- de ingresos en el sector.

- Considerando que el programa de crédito de ser aulofinanciable y que el principal problema de los microempresarios no es el costo de los recursos sino mas bien la exclusión de los sistemas y programas de apoyo financiero, es evidente que no deberán considerarse tasas de interés subsidiadas y que eslas además deberán como minimo cubrir los costos financieros y operalivos del programa global.

La ESTRUCTURA OPERATIVA del programa podria considerar los siguientes elementos:

- La modalidad inslitucional mas apropiada sería la de una estructura similar al Fondo de Inversión Social, con el objeto de lograr el máximo nivel de apoyo político (la Presidencia de la República) y el mayor grado de autonomia operaliva financiera. Sin embargo, para ganar en participación sería necesario que se considerase la ampliación del Consejo de Administración y que la designación de algunos de los Directores por parte del Presidente de la República se realizase entre personas de reconocida capacidad, propuestas por el Consejo Asesor del Programa.

- El Consejo Asesor podria estar integrado por cualro representantes de Universidades y de Centros de Investigación de reconocido prestigio nacional -que tengan programas de investigación sobre microempresa y sector informal -y también por Ires representanles de las gremiales microempresariales y un representante del Ministerio de Planificación Económica. Esle Consejo sería conformado al momento de creación institucional del Fondo y podría tener como miembros honorarios (sin voto) a representantes de las principales federaciones de ONG con experiencia y trabajo con el sector inlormal.

- Las lunciones básicas de este consejo asesor serian:

- Asesorar al Consejo de Administración en el diseño de las macropolíticas para el sector informal y en las políticas de acción del Fondo.

- Apoyar ante el Gobierno las medidas que el Consejo del Fondo considere necesario implementar en siluaciones adversas o de emergencia que afecten el cumplimienlo de sus objetivos lundamentales. 
- Constituirse en intermediario frente a los grupos de presión (comunales y corporativos) que tienen interés en obtener determinados resultados de la polílica aplicada y que por tanto actúan activamente para moldearla indireclamente. Apoyar al Fondo trente a los diferentes actores del sector con el objelo de potenciar la interacción de todos los actores involucrados en el campo de acción de las políticas de apoyo.

- Apoyar, ante las organizaciones internacionales de asistencia técnico-financiera, las gestiones encaminadas a consolidar y ampliar los recursos del Fondo.

- Conocer y evaluar los informes anuales de la institución responsable del programa (Fondo).

- En tanto que el Fondo sería responsable ultimo del Programa, la responsabilidad del disefio de las políticas y proyectos sería centralizada en esta institución - lo cual no omile que el proceso de planificación sea de lipo consultivo/integrador- el proceso de ejecución sería descentralizado (con dilerentes agentes de ejecución) y la supervisión, del proceso de ejecución y cumplimiento de metas, correspondería al Fondo.

- Para ser una institución ágil es preciso que el núcleo básico de personal (dirección ejeculiva y personal técnico) sea reducido al mínimo indispensable para cumplir eficienlemente sus funciones. También es necesario considerar que a pesar de que no será una instilución ejecutora será preciso conlar con personal de campo que estaría a cargo de la planificación regional/local y de promover las iniciativas locales de desarrollo. Esto implica algún grado de descentralización (o regionalización) de las oficinas y/o equipos técnicos que se encargarian de coordinar las acciones de apoyo con los actores locales: ONG que lienen experiencia de trabajo en la región, las oficinas gubernamentales regionales/locales, las comunidades o agentes productivos y las sucursales del sistema financiero involucrado en la ejecución del programa.

- Finalmente la eslructura operativa debe de acomodarse al manejo de recursos no reembolsables (provenientes de asignaciones liscales) a los cuales podrian acceder asociaciones sin lines de lucro formadas exclusivamenle para crear y manejar INCUBADORAS de microempresas.

Resumiendo, la finalidad ullima de este PROGRAMA seria la de crear un marco inslitucional que refleje la volunlad político-social de apoyo a los microproductores y que a su vez sea lo suficientemente abierto 
y flexible para incorporar las diferencias estructurales existentes y los cambios que vaya presenlando la realidad sobre la que se actuja.

\section{BIBLIOGRAFIA}

Alvarez, I. et All. (1988) Alcances y Límites del Financiamiento al Sector Intormal: Ramas Industrial y Servicios. Tesis Licenciatura. Economla. Universidad Centroamericana José Simeón Cañas. El Salvador.

Briones, C. (1989). La Petite Production Marchande et l'Emploi; dans le Secteur Informel: Le cas d'une Economie à Croissance Extravertie. Tesis de Doclorado. Economia, París, Inédita.

Briones, C. (1991). "Economla Informal en el Gran San Salvador" en Pérez Sainz. J.P. y Menjivar Larin, R. "Informalidad urbana en Centroamérica, entre la acumulación y la subsistencia". Caracas, Venezuela. FLACSO.

Briones, C. (1992). La Pobreza Urbana en EI Salvador. UCA-EDITORES, EI Salvador.

Castiglia, Miguel Angel (1992). "La Arquitectura de los Programas Nacionales de Apoyo a la Microempresa: un modelo deseable" en "Información y Pobreza". San José, Cosla Rica. FLACSO.

Hugon, Ph. el All (1977). La Petite Production Marchande et l'Emploi dans le secleur Informal: le cas Africain. IEDES, Univ. Parls I, París.

Krilz, E. (1985). De la Economía de Subsistencia a la Lógica de Acumulación. Criterios de Elegibilidad para Programas de Desarrollo Microempresarial. OIT/PNUD Lima, Perú.

López, H. et All. (1990). "El Impacto del Crédito sobre el empleo y los ingresos de la Microempresas en Colombia", en lecciones sobre Crédito al Sector Informal. Santiago, Chile.

Ministerio de Planificación (1986). Encuesta de Hogares de Propósitos Múltiples. AMSS Vol. III.

Pérez Sainz, J.P. (1991). Informalidad Urbana en América Latina. Enfoques, Problemáticas e Interrogantes. Caracas, Venezuela, FLACSO.

Zarca, B. (1982). "Rationalité économique des Artisans" in Consommation-Revue de Socio-économie № 1, París. 